\author{
Short Communicatrons
}

\title{
Paper Chromatographic Separation of Glucosamine and Galactosamine
}

Methods for the identification of glucosamine and galactosamine have become important since they have been shown to be present in blood group substances and other glycoproteins. In our studies on the chemical composition of a basement membrane mucopolysaccharide containing a hexosamine (1), paper chromatography with solvents reported in literature, namely, butanol-pyridine-water $(6: 4: 3)$ (2), pyridine-ethyl acetate-acetic acid-water $(5: 5: 1: 3)(3)$, or $1 \%$ aqueous ammonia in phenol $(\mathrm{v} / \mathrm{w})(4)$, proved to be unsatisfactory as the separation of glucosamine and galactosamine was slight and was invariably accompanied by trailing. Satisfactory results were, however, obtained with the modified solvents system: ethyl acetate-pyridine- $n$-butanol-butyric acid-water (10:10:5:1:5) (Fig. 1). In these experiments, aqueous solutions of the two hexosamine hydrochlorides and their mixture were compared with an acid hydrolyzate of the mucopolysaccharide ( $5 \mathrm{~N}$ $\mathrm{HCl}, 100^{\circ} \mathrm{C}, 8 \mathrm{hr}$ in sealed tubes) from which neutral sugars and amino acids were removed by the method of Boas (5). The solutions were spotted on a Whatman No. 1 paper and developed for $24 \mathrm{hr}$ at room temperature in a descending manner, the solvent being allowed to run off the paper. The hexosamines were located on the air-dried paper strips with a silver nitrate reagent (6). Under these conditions, the distances traveled by glucosamine and galactosamine were 21.3 and $18.2 \mathrm{~cm}$, respectively.

\section{ACKNOWLEDGMENT}

These studies were supported by University of Michigan Cancer Research Institute and H. H. Rackham Project, R-635.

\section{REFERENCES}

1. Mukerjee, H., Pierce, G. B., and Sri Ram, J., Federation Proc. 23, 235 (1964).

2. Crumpton, M. J., Biochem. J. 72, 479 (1959). 


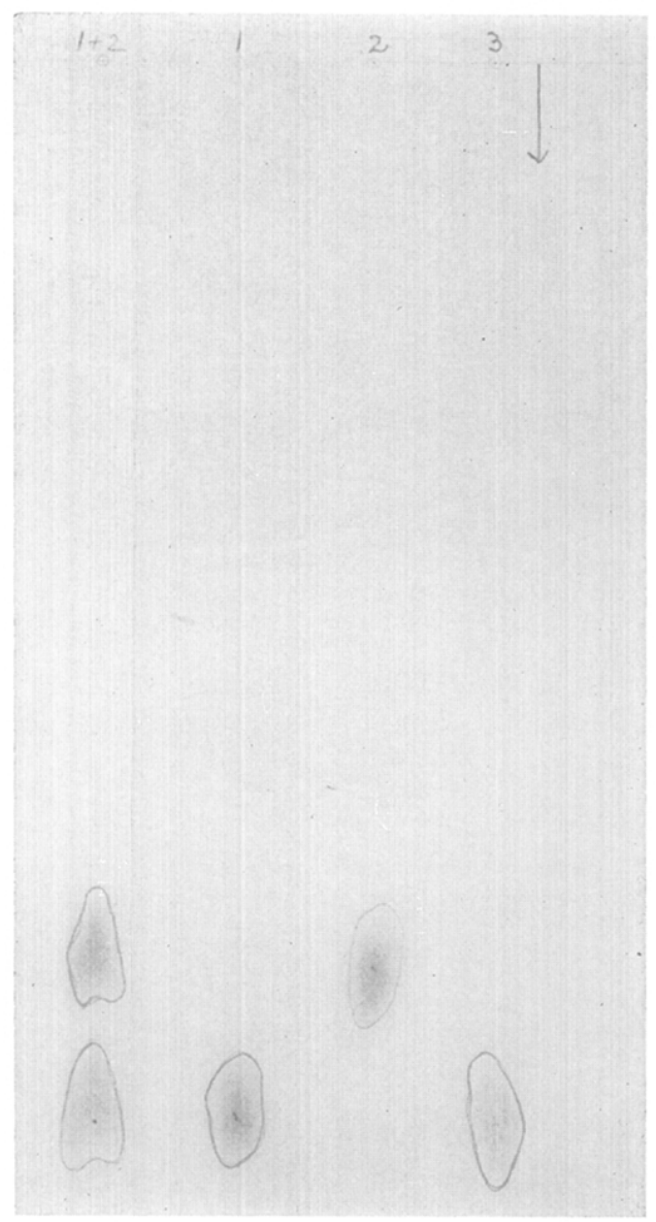

Fig. 1. Paper chromatography of glucosamine (1), galactosamine (2), and an acid hydrolyzate of basement membrane mucopolysaccharide (3). Solvent: ethyl acetatepyridine- $n$-butanol-butyric acid-water $(10: 10: 5: 1: 5) ; 3-5 \mu \mathrm{g}$ of the hexosamines were applied.

3. Kabat, E. A., ANd Mayer, M. M., "Experimental Immunochemistry," 2nd Ed., p. 515. C. C Thomas, Springfield, Ill., 1961.

4. Patridge, S. M., Biochem. J. 42, 251 (1948).

5. Boas, N. F., J. Biol. Chem. 204, 553 (1953).

6. Trevelyan, W. E., Proctor, D. P., and Harrison, J. S., Nature 166, 444 (1950).

Department of Pathology

H. MUKerJeE ${ }^{1}$

J. SRI RAM

The University of Michigan

Ann Arbor, Michigan

Received March 16, 1964

${ }^{1}$ E. U. Pardee Foundation Postdoctoral Rezearch Fellow. 